\title{
The influence of finishing and softening treatments on the sensory properties of denim fabric
}

\author{
Abdelfatah Halleb Naima ${ }^{1 *}$, Sahnoun Mehdi ${ }^{1}$, Cheikh Rouhou Mourched $^{1}$ \\ University of Monastir, Textile Engineering Laboratory, Tunisia
}

Corresponding Author: Abdelfatah Halleb NAIMA, Naimahalleb2005@yahoo.f

\begin{abstract}
The notion of hand or touch of the fabric depends on several parameters starting with the raw material ending with the finishing techniques and treatments. Several treatments of finishing, accomplished on fabric have an effect on its handle. The purpose of this study is to estimate the effect of two finishing processes and softening treatment on the Denim fabric handle. The first one is a normal finishing, the second is a fifties finishing. A trained panel assessed the tactile sensory properties of treated denim fabrics. This panel took part in a training program. During this program, the panellists' performance in terms of repeatability was controlled to decrease the variability of the provided measurements. This panel assessed 16 sensory attributes already selected to find out the differences between the treated samples. The results of sensory evaluation were studied using the principal components analysis (PCA) and analysis of variance (ANOVA). According to the results, the change of denim fabric handle is more important in the case of fifties finishing than the normal finishing processes. This study also shows that the effect of softener is more legible in the case of fifties finishing and the low concentration of fabric softener did not influence the handle of denim fabric. This paper identifies the most important tactile sensory properties that are influenced by industrial finishing for the denim fabric. This paper represents as well the handle progressive changes that occur when treating the denim fabric with various finishing.
\end{abstract}

\author{
ARTICLE HISTORY \\ Received: 25.08 .2018 \\ Accepted: 26.12 .2018
}

\section{KEYWORDS}

Finishing, softening, sensory analyse, sensory properties, handle, denim fabric

\section{INTRODUCTION}

The most important characteristics that affect the apparel products quality and influences the consumer's decisionmaking process is the tactile property. Several processes in textile finishing involve a modification on fabric sensorial and mechanical properties.

The characterization of the hand of a fabric has remained one of the big concerns of textile research since the thirties (Peirce, 1930). Some researches were conducted to study the influence of finishing treatments on the handle of weaved or knitted fabric. Colina et al (1999) quantified, using subjective and objective evaluation methods, the tactile and mechanical properties of $1^{*} 1$ rib knitwear fabrics (acrylic, cotton, and wool) which were subjected to different techniques of laundering in a variety of washing and drying conditions. In 1997, Bueno evaluated objectively, by means of the KES-F (Kawabata, 1980), the effects of emerizing and scratching on the surface properties of plain weave fabric.
She characterized the defect due to the irregularities of these treatments. She applied the same methodology with other researchers (Bueno et al. , 1997) to quantify the effects of calendering, shearing and raising on the plain fabric. Jevsnik et al. (2011) used the KES-F to evaluate the effects of cellulose treatment on the weft knitted fabric regarding mechanical and surface properties. The influence of enzyme treatments, friction, and geometrical roughness on the face and reverse side of interlock knitted fabrics were discussed in comparison with untreated interlock knitted fabrics. Agarwal et al. (2011) also used the Kawabata evaluation system for fabric (KES-F) and universal surface tester (UST) to evaluate the low-stress mechanical properties, in order to examine the influence of ageing and the fabric softener used during the wash cycles of knitted fabrics. Philippe et al. (2003) compared the effect of some type of softener on the sensory feeling of fabrics. They assumed that fabrics treated by a macro emulsion softener are greasier than fabrics treated by the micro emulsion

To cite this article: Naima A. H., Mehdi S, Mourched C. R., 2018, "The influence of finishing and softening treatments on the sensory properties of denim fabric" Tekstil ve Konfeksiyon, 29 (1), pp: 58-66. 
softener. In the work of Strazdiene et al. (2006) the effect of two finishing products (the crease-resistant finishing Knittex "K" and the softener macro Silicone Ultratex "UI") upon 100 $\%$ cotton plain weave fabric was studied with two methods; objective evaluation (Griff tester) and sensory analysis (by a panel of 11 trained subjects). Objective evaluation was done using a Griff tester device where disc-shaped specimen was extracted through a rounded hole of the stand. Sensory analysis was performed by a panel of 11 trained subjects. Tarhan and Sariisik (2009) studied the effects of sand blasting, laser application and enzyme silicone wash on fabric physical properties, hand, breaking and seam strengths and fabric stiffness. Özgüney et al (2009) are examined objectively the effects of different kinds of finishing treatments on the hand properties of the woven fabrics produced with compact spun yarns. Utlu Ala and İkiz (2017) are assessed objectively and subjectively the effect of selected fabric structural parameters and domestic laundering operations on the preference of woven terry fabrics. Sular and Kaplan (2011) studied the influences of some washing (rinse, enzyme wash, stone, bleach) and special treatment processes on some physical, mechanical properties and hand of two types of denim fabrics. A pane composed of 10 graduate students of textile using a fivepoints rating scale conducted hand evaluation. Halleb et al. (2015) evaluated the effect of four different washes (rinse, stone, double stone and stone bleach) on the denim fabric tactile properties using a sensory analysis. The tactile sensory properties of washed denim fabrics were assessed by trained panel composed of ten assessors.

In this work, we have focused only on the influence of the finishing treatments and softening on the denim fabric handle using a trained panel. Previously, the studied fabrics were subjected to two different finishing processes with or without softening. The studied finishing were namely; normal finishing and fifties finishing. In order to determine the difference between the treated samples, we asked our trained panel composed of ten assessors to score a list of already defined sensory attributes. It is thought that results would be beneficial for scientists conducting studies on denim finishing and tactile properties. Moreover, results may guide denim producers in selecting the optimum application for required aesthetic appearances.

\section{MATERIALS AND METHODS}

\section{Characteristics of the Evaluated Fabric}

The judges are trained to assess all kinds of textile materials. However, in this work, we assessed only one structure, it is the twill 3/1 (denim) $100 \%$ cotton. The following table summarizes the physical properties that identify this fabric.

Table 1. Physical properties of Denim Fabric

\begin{tabular}{|l|l|l|}
\hline Weave & $3 / 1$ Twill \\
\hline Composition; & $100 \%$ cotton \\
\hline Weight; $\mathbf{g} \mathbf{m}^{\mathbf{2}}$ & 451 & \\
\hline Yarn linear density; $\mathbf{N m}$ & Warp & 12.5 \\
\cline { 2 - 3 } & Weft & 13 \\
\hline Thread density; $\mathbf{c m}$ & $27-17$ & \\
\hline
\end{tabular}

When just woven, fabric is rough and hard. Before becoming final products, the fabric needs to undergo various mechanical and/or physic-chemical treatments
(Pietro et al., 2001). In the case of denim fabric, treatments are realized in a quasi-systematic way followed by finishing treatments. They are made before the clothing production, in order to modify the state of fabric surface, to change aesthetic appearances of denim products and to award the final quality wanted to the treated material.

The assessed samples were subjected to normal and fifties finishing processes. After that, two concentrations $\left(30 \mathrm{~g} / \mathrm{m}^{2}\right.$ and $60 \mathrm{~g} / \mathrm{m}^{2}$ ) and two types of fabric softeners (acrylic resin and natural acrylic) were used for these samples. In total, eight different samples were assessed; two untreated with softeners and six of them were treated by softeners. Table 2 represents the assessed samples and their appropriate treatment.

Table 2. The assessed samples

\begin{tabular}{|l|l|l|}
\hline \multicolumn{1}{|c|}{$\begin{array}{c}\text { Fabric } \\
\text { Name }\end{array}$} & $\begin{array}{c}\text { Finishing } \\
\text { Process }\end{array}$ & \multicolumn{1}{c|}{$\begin{array}{c}\text { Softener } \\
\mathbf{g} / \mathrm{m}^{2}\end{array}$} \\
\hline $\mathrm{Nb}$ & Normal & 0 \\
\hline $\mathrm{N} 30 \mathrm{R}$ & Normal & $30 \mathrm{~g} / \mathrm{m}^{2}$ acrylic resin \\
\hline $\mathrm{N} 60 \mathrm{R}$ & Normal & $60 \mathrm{~g} / \mathrm{m}^{2}$ acrylic resin \\
\hline $\mathrm{N} 60 \mathrm{~N}$ & Normal & $60 \mathrm{~g} / \mathrm{m}^{2}$ natural acrylic \\
\hline $\mathrm{Fb}$ & Fifties & 0 \\
\hline F30R & Fifties & $30 \mathrm{~g} / \mathrm{m}^{2}$ acrylic resin \\
\hline F60R & Fifties & $60 \mathrm{~g} / \mathrm{m}^{2}$ acrylic resin \\
\hline F60N & Fifties & $60 \mathrm{~g} / \mathrm{m}^{2}$ natural acrylic \\
\hline
\end{tabular}

\section{The normal finishing}

The normal finishing consists of a Denim Range treatment followed by a sanforizing:

- Denim Range: this is a treatment of fabric in a bath of finishing factors in the presence of a straightening mechanism, which permits one to exercise a high tension to fix the angle of movement between the warp and the weft yarns. This treatment allows us to increase the density of fabric and makes the fabric more like cardboard.

Sanforizing: this is a treatment to increase dimensional stability of textile materials. The sanforizing allows us to make the cotton fabrics less fragile to the wash, in particular as regards to their shrinkage and the possible loss of colors. During this operation, fabrics are stretched in length as well as in width so that they do not shrink after the first wash.

\section{The fifties finishing}

The fifties finishing is a process of finishing that begins with a treatment on mercerizing range machine (Goller) in the presence of $\mathrm{NaOH}(160 \mathrm{~g} / \mathrm{l})$ and at a low temperature $10^{\circ} \mathrm{C}$, followed by rinsing and neutralization. This treatment permits a partial desizing of fabric and makes it flatten, dense, smooth and brilliant, as it increases the fabric's dynamic resistance and the unification of dye. This finishing process ends in a Denim Range and a sanforizing treatment, same case as of normal finishing.

\section{The softening}

The softening is an organoleptic treatment. It has for objective to give a pleasant handle to the fabric. There are several types of fabric softeners, which can achieve this 
objective. The common point to all these fabric softeners is a grease aliphatic chain existing in their molecule. These long grease chains possess a hydrophobic character. During the softening process, these chains form a grease overcoat that covers the textile surface. This process makes the fabric saturated. These fabric softeners can be either to adhere by the coating of the textile surface, or to passive the textile materiel.

The surfaces of the studied fabrics are coated with softener foam. This treatment is made by means of an industrial machine.

In this work, we studied two types of fabric softener:

- Acrylic Resin: it improves the fabric handle, but it gives a greyish aspect.

- Natural Acrylic: it makes the fabric softer and gives it a natural indigo color.

\section{Conditions of the sensory evaluation}

With the aim of studying the effect of the treatments described previously on the handle of denim fabrics, sixteen samples $(8 \times 2)$ were assessed during four sessions. And in order to minimize errors arising from fatigue, only four samples were assessed during each session.

Before the evaluation, swatches (dimension $30 \mathrm{~cm} \times 20 \mathrm{~cm}$ ) are kept in the standard condition $\left(T=20 \pm 2^{\circ} \mathrm{C}\right.$ and
$\mathrm{H}=65 \pm 2 \%$ ) for 24 hours. A panel of ten trained members evaluated the sensory properties of these samples. A PCA and ANOVA analyses were carried out to set up this group of ten-textile handle experts. They were selected among fifteen trained judges according to their repeatability (standard deviation $<0,8$ ) and discriminative capacity. Sixteen attributes were assessed using a structured linescale (from 0 to 10) and in accordance with assessment methods predefined for each attribute.

These fabric attributes, specific to denim fabric evaluation, were selected after qualitative and quantitative reductions of a list of 56 tactile attributes (Halleb, 2013), which were generated following a preliminary questionnaire of 200 peoples (of different age, sex and experience). For each attribute, the assessment method was defined through qualitative discussions with the panelists. The panelists were then trained in the quantification of each tactile attribute, in order to prove the consistency of panellists' evaluation and variability between panellists. The 16 fabric tactile sensory properties and their assessment methods are presented in Table 3.

The handle fabric was assessed in a specific cabinet. The evaluated fabric sensory attributes were predominantly tactile without sight. The fabric swatches were presented in random order. Before handling fabrics, the panellists were required to wash and dry their hands.

Table 3. The list of attributes

\begin{tabular}{|c|c|c|c|c|c|c|c|}
\hline & \multicolumn{3}{|c|}{ Categories } & \multirow[t]{2}{*}{ Attributes } & \multicolumn{2}{|c|}{ Reference } & \multirow[t]{2}{*}{ Assessment technique } \\
\hline & surface & physic & dynamic & & negative & Positive & \\
\hline \multirow{5}{*}{ 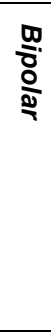 } & * & & & Cold-heat & $\begin{array}{l}\text { Glass or } \\
\text { leather }\end{array}$ & Wool & $\begin{array}{l}\text { To take the sample suspended with full } \\
\text { hand }\end{array}$ \\
\hline & * & & & Moist-dry & & Wool & $\begin{array}{l}\text { To take the sample suspended with full } \\
\text { hand }\end{array}$ \\
\hline & & * & & Thin-thick & Veil & $\begin{array}{l}\text { Velvet of } \\
\text { furnishing }\end{array}$ & $\begin{array}{l}\text { To estimate the thickness with the thumb } \\
\text { and index finger }\end{array}$ \\
\hline & & * & & Light-heavy & Veil & $\begin{array}{l}\text { Fabric } \\
\text { furnishing }\end{array}$ & $\begin{array}{l}\text { To weigh with the hand the mass of the } \\
\text { sample. }\end{array}$ \\
\hline & * & & & $\begin{array}{l}\text { Smooth- } \\
\text { grooved }\end{array}$ & Paper & $\begin{array}{l}\text { Fabric } \\
\text { furnishing }\end{array}$ & $\begin{array}{l}\text { To estimate the relief and the grooves } \\
\text { with the end of the thumb. }\end{array}$ \\
\hline & & & * & Supple-stiff & $\begin{array}{l}\text { Viscose and } \\
\text { lycra Jersey }\end{array}$ & Raw Twill & $\begin{array}{l}\text { To handle and to compress the fabric with } \\
\text { the two hands. }\end{array}$ \\
\hline \multirow[t]{10}{*}{$\frac{\substack{D \\
\frac{3}{3}}}{c}$} & & * & & Falling & Raw Twill & $\begin{array}{l}\text { Viscose and } \\
\text { lycra Jersey }\end{array}$ & $\begin{array}{l}\text { To take the closed hand, if it open while } \\
\text { passing on the suspended fabric, } \\
\text { therefore not falling. }\end{array}$ \\
\hline & & & * & Flexible & Raw Twill & $\begin{array}{l}\text { Viscose and } \\
\text { lycra Jersey }\end{array}$ & $\begin{array}{l}\text { The sample is held between two fingers in } \\
\text { one hand and swept from top to bottom } \\
\text { with the palm of the other hand. }\end{array}$ \\
\hline & * & & & Tender & Raw Twill & Cashmere & $\begin{array}{l}\text { To graze with the fingers and the palm of } \\
\text { hand }\end{array}$ \\
\hline & * & & & Silky & Raw Twill & Silk satin & To rub gently with the fingers and thumb \\
\hline & * & & & Sleek & & Satin & $\begin{array}{l}\text { To make flat pass the fingers on the } \\
\text { fabric, it is smooth when there is not } \\
\text { roughness. }\end{array}$ \\
\hline & * & & & Slippery & & Paper & $\begin{array}{l}\text { To move the palm of the hand across the } \\
\text { surface of the sample. }\end{array}$ \\
\hline & * & & & Hairy & Paper & Angora & $\begin{array}{l}\text { To estimate the density and the length of } \\
\text { fibers at the surface of the fabric with the } \\
\text { ends of the fingers }\end{array}$ \\
\hline & & & * & Elastic & Paper & $\begin{array}{l}\text { Viscose and } \\
\text { lycra Jersey }\end{array}$ & $\begin{array}{l}\text { The edges of the sample are held with } \\
\text { both hands then stretched for three times } \\
\text { in the same direction. }\end{array}$ \\
\hline & * & & & Compact & & Paper & $\begin{array}{l}\text { To check the density of the fabric with the } \\
\text { ends of fingers. }\end{array}$ \\
\hline & & & * & Wrinkly & & Paper & $\begin{array}{l}\text { To get the sample into one hand and to } \\
\text { compress, open the fabric and check if } \\
\text { the folds persist. }\end{array}$ \\
\hline
\end{tabular}




\section{RESULTS AND DISCUSSIONS}

To reach the purposes of this work, analyses of variance (ANOVA) in two factors and principal components analyses (PCA) were carried out to define the most pertinent attributes and a Duncan test was applied to compare and classify the assessed fabrics.

The ANOVA allowed us to calculate $F$ fabric and $F$ interaction ( $F$ was statistical of Fisher Snedecor). The $F$ fabric allows to know if the subjects will perceive the difference between fabrics. If $F$ fabric is significant the fabrics can be considered as different. The $F$ fabric was defined as follows:

$$
\text { Ffabric }=\frac{\frac{r \sum_{i=1}^{p}\left(\overline{Y_{i j}}-\overline{Y_{j}}\right)}{p-1}}{\frac{\sum_{i=1}^{p} \sum_{k=1}^{r}\left(Y_{i j k}-\overline{Y_{i j}}\right)^{2}}{p(r-1)}}
$$

Where $Y_{i j k}$ was the score given by panellist $j$ to the evaluation $k$ of the sample $i$. In our case, the number of samples $p=$ four, the number of panellists $q=10$ and the number of evaluation for the same samples $r=2 . \bar{Y}_{i j}$ was the average of scores for the sample $i$ given by the panellist j:

$$
\bar{Y}_{i j}=\frac{\sum_{k=1}^{r} Y_{i j k}}{r}
$$

The $F$ interaction (equation 3 ) informs about the degree of association between the subjects; if $F$ interaction is not significant, the subjects can be considered as homogeneous in their evaluation for this attribute; therefore, they are considered in agreement. Otherwise, they are in total disagreement. Therefore, a PCA is carried out on the average scores for attributes in disagreements in order to find out the origin of the significance of this interaction.

$$
F \text { interaction }=\frac{\frac{r \sum_{i=1}^{p} \sum_{j=1}^{q}\left(\bar{Y}_{i j}-\bar{Y}\right)^{2}-p r \sum_{j=1}^{q}\left(\bar{Y}_{j}-\bar{Y}\right)^{2}-q r \sum_{i=1}^{p}\left(\bar{Y}_{i}-\bar{Y}\right)^{2}}{(q-1)(p-1)}}{\frac{\sum_{i=1}^{p} \sum_{j=1}^{q} \sum_{k=1}^{r}\left(Y_{i j k}-\bar{Y}_{i j}\right)^{2}}{p q(r-1)}}
$$

Where $\bar{Y}$ was the global average of the scores given by:

$$
\bar{Y}=\frac{\sum_{i=1}^{p} \sum_{j=1}^{q} \sum_{k=1}^{r} Y_{i j k}}{p q r}
$$

$\bar{Y}_{j}$ was the average of the scores for the panellist $j$ :

$$
\bar{Y}_{j}=\frac{\sum_{i=1}^{p} \sum_{k=1}^{r} Y_{i j k}}{p r}
$$

And $\bar{Y}_{i}$ was the average of the scores for the sample $i$ :

$$
\bar{Y}_{i}=\frac{\sum_{j=1}^{q} \sum_{k=1}^{r} Y_{i j k}}{q r}
$$

Table 4 shows that all the attributes have a significant $F$ fabric except elastic and smooth-grooved. This implies that fabrics are different for the majority of these attributes according to the panel. The panel did not make the difference between samples for the attributes elastic and

\begin{tabular}{|c|c|c|}
\hline Attributes & F Fabric & $F$ Interaction \\
\hline Cold-warm & $28.378 \bullet$ & $22.769 \bullet$ \\
\hline Moist-dry & 6.197 & 4.715 \\
\hline thin-thick & $46.747 \bullet$ & 0.964 \\
\hline Falling & $14.006 \bullet$ & 0.332 \\
\hline Tender & $33.627 \bullet$ & $1.79 \bullet \bullet \bullet$ \\
\hline Silky & $142.544 \bullet$ & 8.991 \\
\hline Light-heavy & $43.222 \bullet$ & 1.22 \\
\hline Sleek & $22.996 \bullet$ & 2.75 \\
\hline Slippery & 9.833 & 1.129 \\
\hline Smooth-grooved & 1.629 & 0.925 \\
\hline Hairy & $26.338 \bullet$ & 12.489 \\
\hline Compact & $15.815 \bullet$ & 0.769 \\
\hline Flexible & $74.599 \bullet$ & $2.775 \quad \bullet \bullet$ \\
\hline Elastic & 1.034 & 0.481 \\
\hline Supple-stiff & $39.585 \bullet$ & 1.304 \\
\hline Wrinkly & 86.31 & $4.422 \bullet$ \\
\hline
\end{tabular}
smooth-grooved. This can be explained by the fact that tested fabrics have the same structure. These two attributes will not be taken into account there, for the later statistical study, although they have not a significant $F$ interaction.

Table 4. Results of ANOVA to 2 factors

- : F statistically significant at 95\% confidence level

The cold-warm, moist-dry, tender, silky, sleek, hairy, flexible and wrinkly attributes present a significant $F$ interaction. This means that panellists estimated the fabrics differently for these attributes. For each of these attributes the circle of correlation (subject PCA variable and fabrics individuals) was represented, in order to determine the origin of disagreement between the panellists.

For the attribute cold-warm the panellists are scattered on the circle of correlation (Figure1). Then, they are completely disagreeing on the evaluation of fabrics. This attribute cannot be interpreted. For that reason, it will not be taken into account in the statistical studies later. As for the moistdry attribute (Figure2), about which the panellists less disagree, but it will not also be taken into account.

However, the panellists are positively correlated on the axis F1 of the circle of the silky attribute (Figure 3 ) except the panellist $\mathbf{m m}$. This judge did not make differences on two fabrics among eight. But the agreement can be considered global, thus this attribute will be taken into account during the later static studies. 


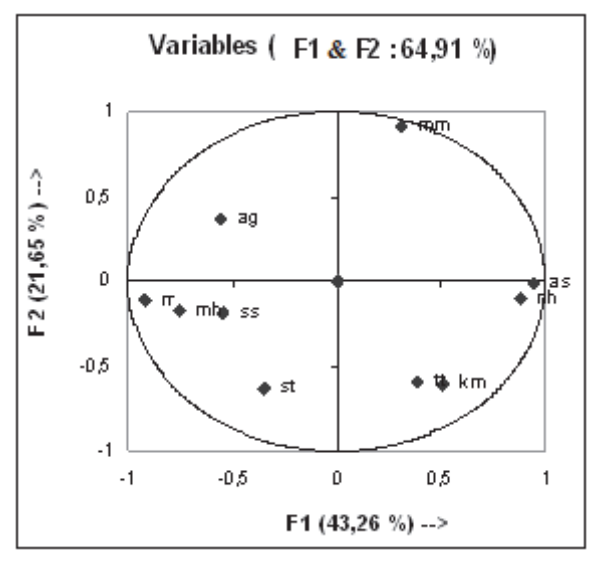

Figure 1. Cold-warm

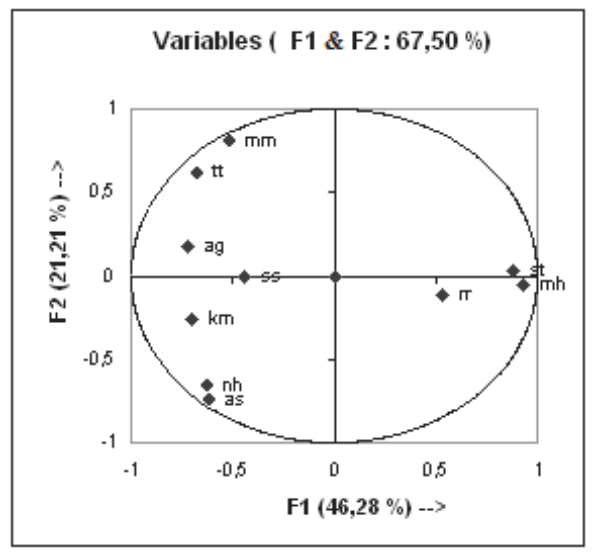

Figure 2. Moist-dry

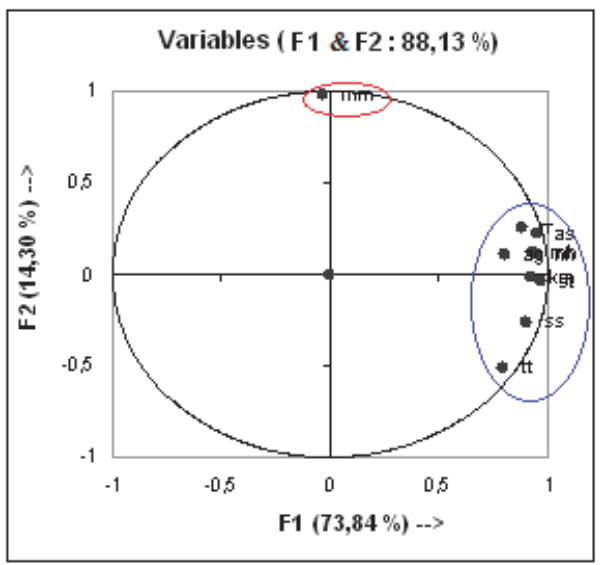

Figure 3. Silky

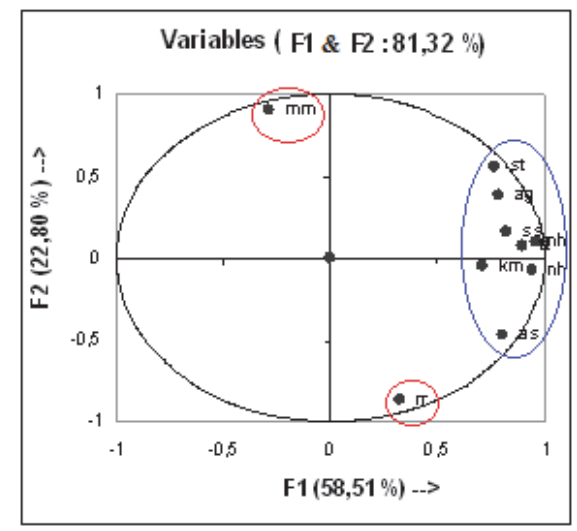

Figure 4. Sleek
For the sleek attribute (Figure 4), the panellists' $\mathbf{m m}$ and $\mathbf{~ r r}$ are a bit far from the others because they are not in agreement with the others on the ranking of some fabrics. All the same, we kept this attribute because the panellists are globally in agreement on the evaluation of fabrics.

Figure 5 shows that the panellists totally disagreed about the evaluation of fabrics for the hairy attribute. Thus, this attribute will be eliminated during the later statistical studies.

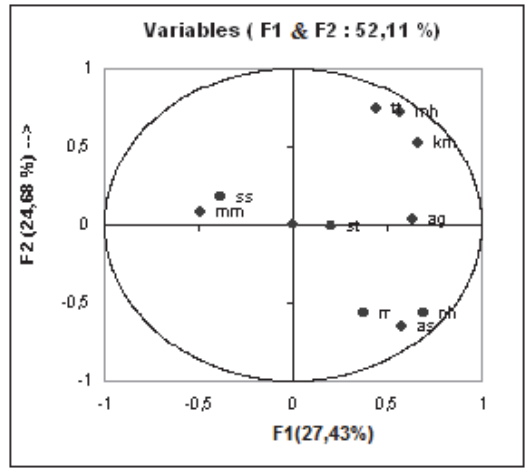

Figure 5. Hairy

However, figure 6 shows that the agreement is global for the flexible attribute because the panellists are highly positively correlated with each other. This attribute will be considered in the following statistical studies.

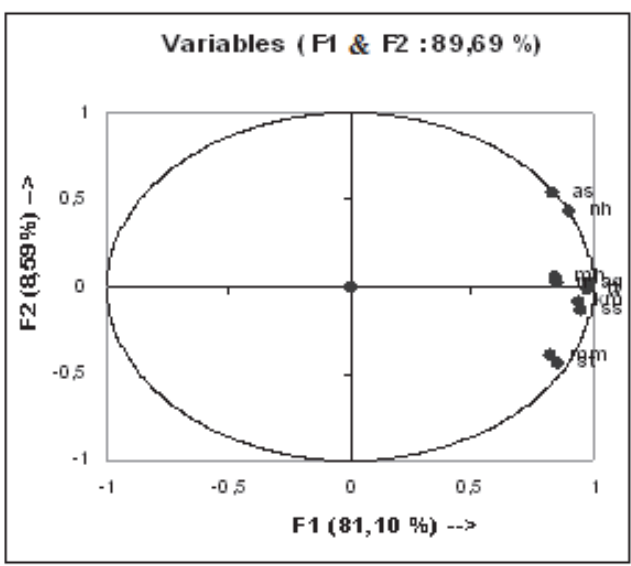

Figure 6. Flexible

The wrinkly attribute (Figure 7) will also be taken into account. For this attribute the panellists present a slight disagreement due to the panellists' $\mathbf{m m}$ and $\mathbf{t t}$, but the agreement is global for the majority of the panellists on the evaluation of fabrics.

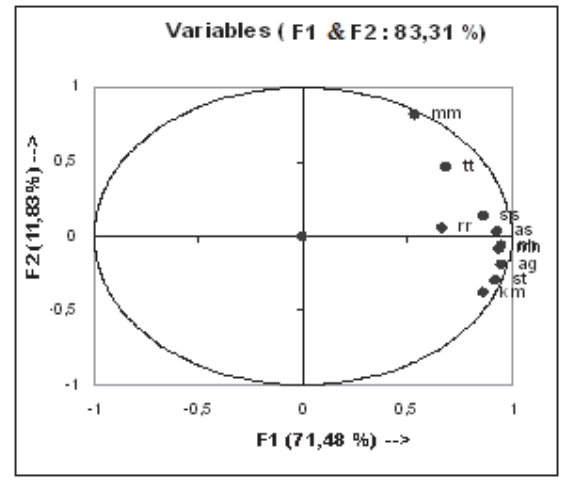

Figure 7. Wrinkly 
According to the previous interpretations, the attributes to be taken into account are the ones which present a nonsignificant $F$ interaction and a significant $F$ fabric. The discriminated attributes are then: thin-thick, falling, tender, silky, sleek, light-heavy, slippery, compact, flexible, supplestiff and wrinkly.

For these attributes, a global PCA is realized on the average notes of the trained panel. The PCA permitted to project a multidimensional data (11 size) onto the plane of two dimensions (axes F1 and F2) that account for the greatest percentage of the variance in the data. According to the curve of the appropriate values (Figure8), the important percentage of information is accumulated on the axes F1 $(95.51 \%)$.

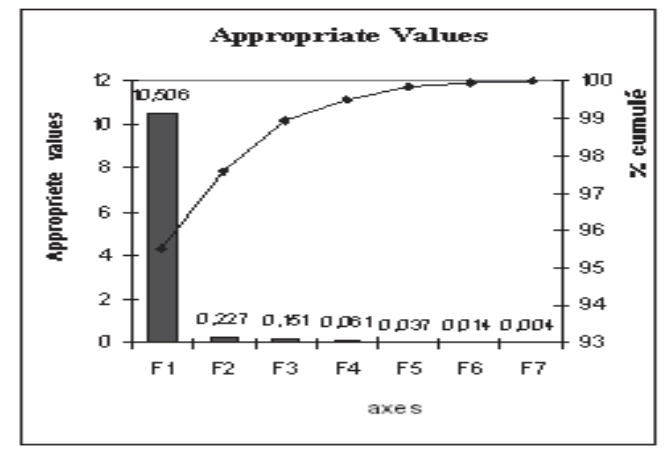

Figure 8. The appropriate values

Indeed, the circle of correlation is represented only on the two first axes, which is considered to be adequate for making broad comparisons between the treated fabrics and to give an overall view of all effects of finishing treatments on them.

Eleven attributes form two poles on the extremities of the first axis of the circle of correlation (Figure9). The falling, tender, silky, sleek, slippery and flexible attributes are close together on the positive extremity and diametrically opposed to the other attributes (compact, thin-thick, light-heavy, suplle-stiff and wrinkly) which form the negative pole. This implies that the attributes of the positive pole evolve in the opposite direction of the attributes of the negative pole.

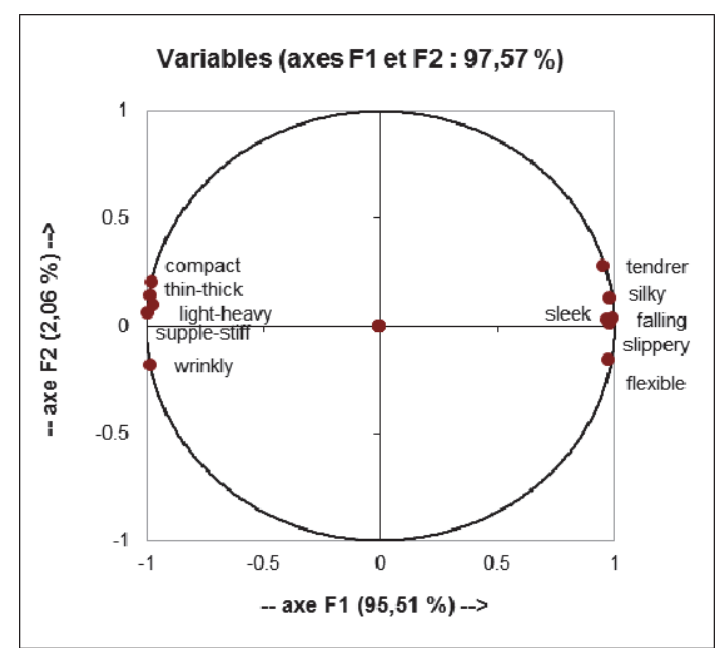

Figure 9. Circle of global correlation
The PCA also allowed us to produce the vectors map of fabrics on these same axes. These maps illustrate the progress of fabric changes through the different finishing treatments. A projection of fabrics on the axes of the discriminating attributes allows to compare them. On this map (Figure 10), the fabrics that are subjected to a fifties finishing process ( $\mathrm{Fb}, \mathrm{F} 30 \mathrm{R}, \mathrm{F} 60 \mathrm{R}$ and $\mathrm{F} 60 \mathrm{~N})$ oppose on the axis $\mathrm{F} 1$ those that are subjected to a normal process (Nb, N30R, N60R and N60N). This shows that; the fifties finishing process improves the falling, tender, silky, sleek, slippery and flexible attributes, and the normal finishing improves the attributes compact, thin-thick, light-heavy, suplle-stiff and wrinkly.

According to this map the untreated fabric by softener $\mathrm{Nb}$ is the wrinkliest, the stiffest, the thickest, the heaviest and the most compact. The fabric $\mathrm{F} 60 \mathrm{~N}$, treated by the natural acrylic fabric softener, was judged to be the tenderest, the silkiest and the most falling. The fabrics N30R, N60R and $\mathrm{N} 60 \mathrm{~N}$ were the most compact. This figure also shows that the handle of assessed fabric improves by increasing the concentration of fabric softener in both cases of fifties and normal finishing process. The panel did not make difference between the fabric treated by acrylic resin (N60R) and the fabric treated by natural acrylic (N60N), in the case of normal finishing. However, the panel could feel the difference between F60R and F60N, which are respectively treated with the same softeners, in the case of fifties finishing. This can be explained by the fact that the influence of the natural acrylic softener is more noticeable in the case of fifties finishing. The natural acrylic softener made the fabric silkier, tenderer, more falling, sleeker, more slippery and flexible.

We studied separately the fabrics which are subjected previously to a fifties finishing and the fabrics that are subjected to a normal finishing. Indeed, we applied the PCA for the results of every group of these fabrics.

The maps in figure11 (fabric treated with fifties finishing previously) show that, the fabrics $\mathrm{Fb}$ and F30R are relative to each other. This means that the handle of studied fabric is slightly modified by the concentration of $30 \mathrm{~g} / \mathrm{m}^{2}$. This figure illustrate also that, the vectors of the fabric F60R and F60N opposes diametrically the vector of the fabric untreated with softener $\mathrm{Fb}$.

The same result was proved in the map of the fabric treated with normal finishing previously (figure 12). In the figure 12, the fabrics $\mathrm{Nb}$ and N30R are also correlated but the effect of the concentration of $30 \mathrm{~g} / \mathbf{m}^{2}$ in this case is more significant than in the case of fifties finishing. Similarly the fabrics N60R and N60N opposes diametrically the vector of the fabric untreated with softener $\mathrm{Nb}$. This mean that $60 \mathrm{~g}$ of softener foam had a significant effect on the handle of denim fabric.

The PCA results revealed that $30 \mathrm{~g}$ of softener foam is insufficient to make a remarkable change on the handle of one $\mathrm{m}^{2}$ of fabric. However, for the concentration of $60 \mathrm{~g} / \mathrm{m}^{2}$ the change of handle is significant. 


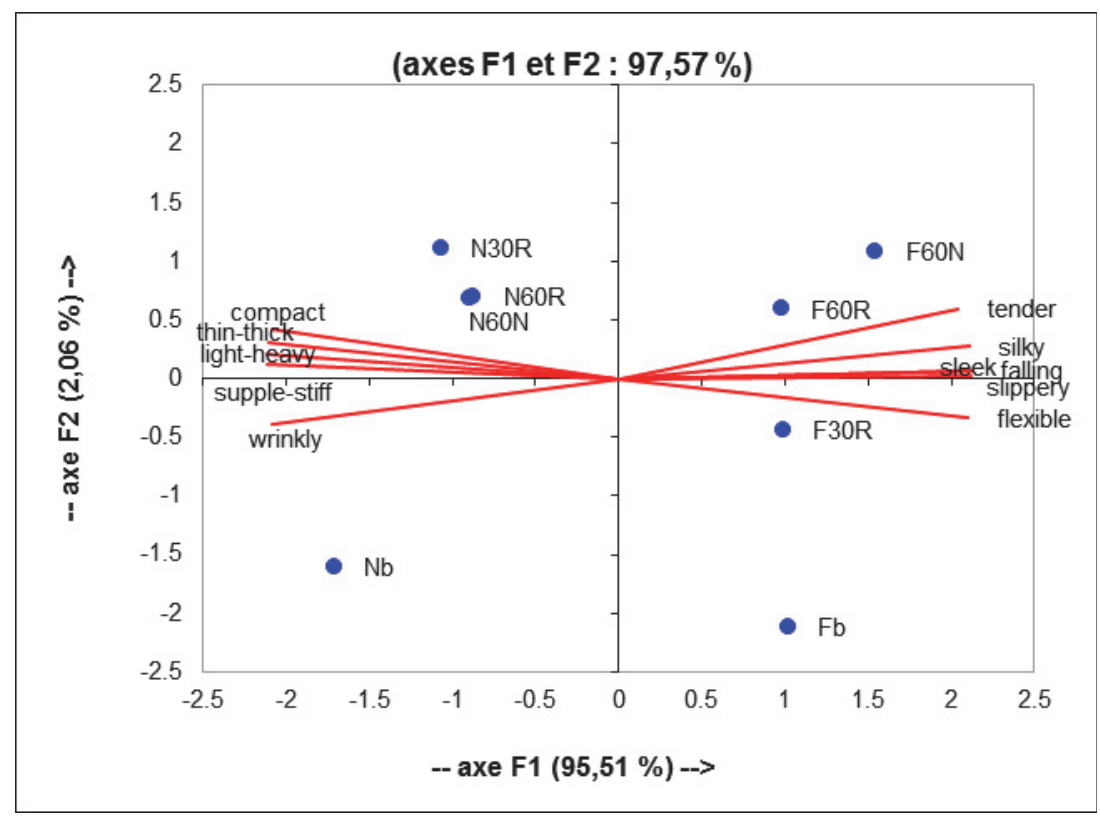

Figure 10. Map of fabrics

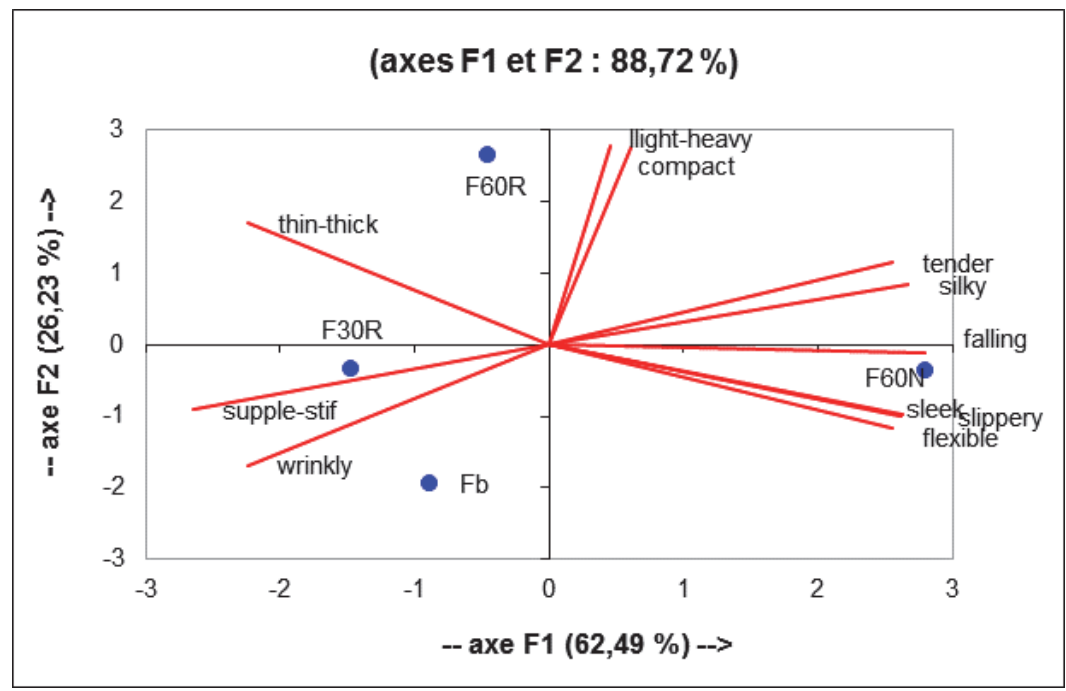

Figure 11. Map of fabrics treated with fifties finishing

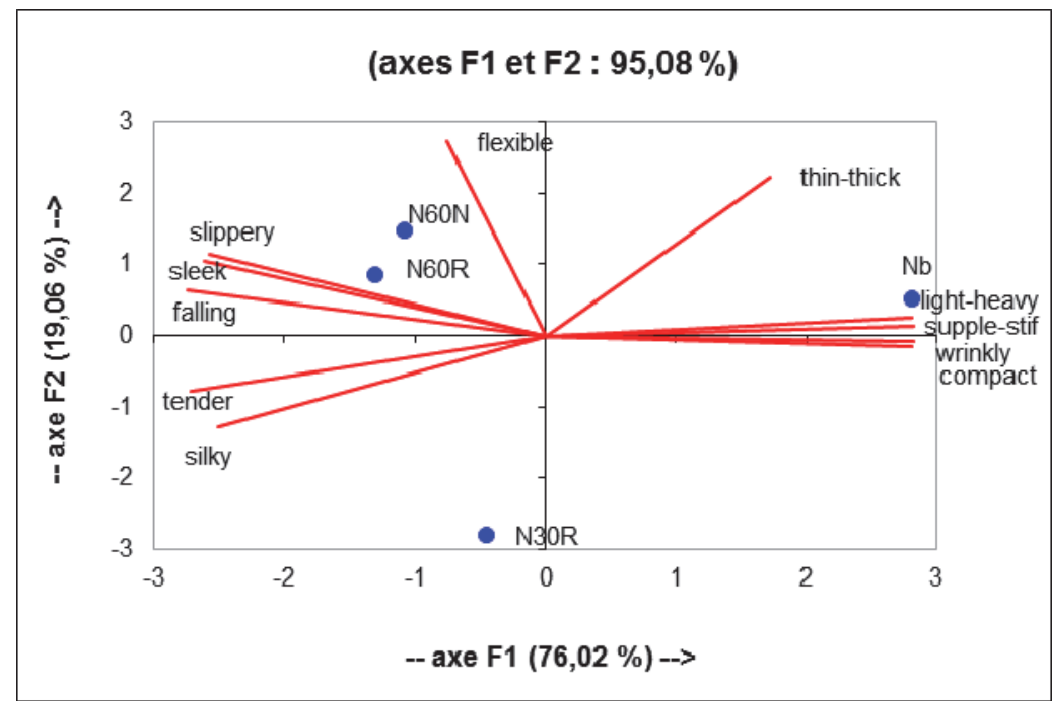

Figure 12. Map of fabrics treated with normal finishing 
The test of multiple comparison of Duncan allowed us to classify the fabrics for each discriminating attribute. According to table 3 , the fabrics are classified into two groups for the thin-thick, light-heavy and compact attributes the first group is formed by the fabrics which are treated with a normal finishing and the second by the fabrics which are treated with a fifties finishing. The fabrics which are treated with a fifties finishing are grouped in the same class for the attribute silky, and they are considered the silkiest. Fabric F60N was considered to be the most falling and fabric 53 the least falling. The same interpretations were noticed for the attributes; tender, sleek and slippery.

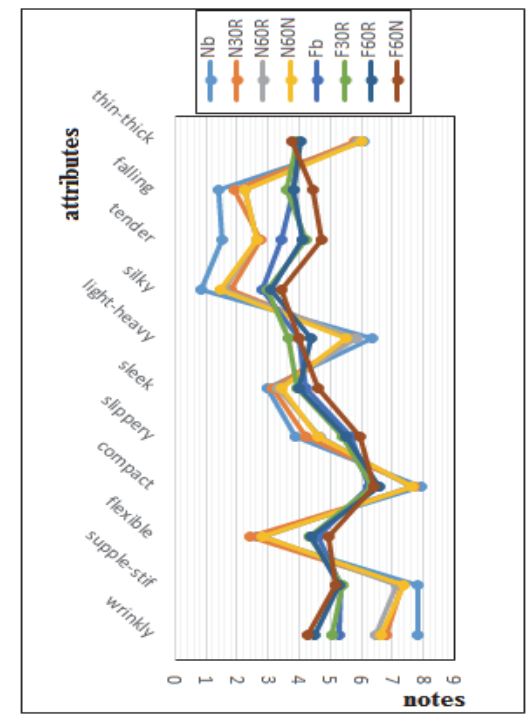

Figure 13. Profiles of fabrics

On the other hand, fabric $\mathrm{Nb}$ was considered to be the most wrinkly, the stiffest and heaviest and fabric F60N the least wrinkly and most supple.
The previous results are confirmed by the profiles of fabrics represented in figure 13 . This figure presents the evaluation of 11 attributes for eight fabrics tested by the panel of experts.

The analysis of these profiles shows that the influence, of the process of finishing as well as the type and the concentration of fabric softener, is significant in the handle of the studied fabric.

\section{CONCLUSION}

According to the previous results, we conclude that the panel perceived significant differences and a distinction was made between fabrics that are treated with a fifties finishing and fabrics that are treated with a normal finishing. This difference can be due to the treatment with $\mathrm{NaOH}$ on Goller (in the case of fifties finishing), which allows to soften the fabric by removing an important percentage of size applied in the yarns during the denim fabric making.

As a conclusion of the study on the concentrations and the types of fabric softeners, the concentration of softener $30 \mathrm{~g} / \mathrm{m}^{2}$ is insufficient to modify enormously the handle of one $\mathrm{m}^{2}$ of fabric. However, for the concentration $60 \mathrm{~g} / \mathrm{m}^{2}$ the change of handle is remarkable. However, the handle of studied fabric improves by increasing the concentration of fabric softener in both cases of fifties and normal finishing processes. The panel did not make difference between the fabric treated by acrylic resin and the fabric treated by natural acrylic in the case of normal finishing. However, it has made difference between those which are respectively treated with the same fabric softeners, in the case of fifties finishing. This can be explained by the influence of the natural acrylic fabric softener which is more legible in the case of fifties finishing.

Table 2. Classification of the fabrics (Duncan test)

\begin{tabular}{|c|c|c|c|c|c|c|c|c|}
\hline & $\mathrm{Nb}$ & N30R & N60R & N60N & $\mathrm{Fb}$ & F30R & F60R & F60N \\
\hline Thin-thick & $\begin{array}{c}6,075 \\
\mathrm{a} \\
\end{array}$ & $\begin{array}{c}5,800 \\
a \\
\end{array}$ & $\begin{array}{c}5,900 \\
a \\
\end{array}$ & $\begin{array}{c}6,015 \\
\mathrm{~A}\end{array}$ & $\begin{array}{c}3,920 \\
\mathrm{~B}\end{array}$ & $\begin{array}{c}3,965 \\
b\end{array}$ & $\begin{array}{c}4,040 \\
\text { b }\end{array}$ & $\begin{array}{c}3,800 \\
B\end{array}$ \\
\hline Failling & $\begin{array}{c}1,440 \\
d\end{array}$ & $\begin{array}{c}1,930 \\
\mathrm{C} \\
\end{array}$ & $\begin{array}{c}2,250 \\
\mathrm{C}\end{array}$ & $\begin{array}{c}2,250 \\
\mathrm{C}\end{array}$ & $\begin{array}{c}3,825 \\
\mathrm{~B}\end{array}$ & $\begin{array}{c}3,600 \\
b\end{array}$ & $\begin{array}{c}3,850 \\
b\end{array}$ & $\begin{array}{c}4,425 \\
\text { A }\end{array}$ \\
\hline Tender & $\begin{array}{c}1,540 \\
\mathrm{~d}\end{array}$ & $\begin{array}{c}2,770 \\
\mathrm{C} \\
\end{array}$ & $\begin{array}{c}2,625 \\
\mathrm{C} \\
\end{array}$ & $\begin{array}{c}2,660 \\
\mathrm{C} \\
\end{array}$ & $\begin{array}{c}3,465 \\
\mathrm{~B} \\
\end{array}$ & $\begin{array}{c}4,240 \\
\mathrm{a} \\
\end{array}$ & $\begin{array}{c}4,100 \\
a b\end{array}$ & $\begin{array}{c}4,725 \\
\text { A }\end{array}$ \\
\hline Silky & $\begin{array}{c}0,825 \\
\mathrm{C} \\
\end{array}$ & $\begin{array}{c}1,785 \\
b\end{array}$ & $\begin{array}{c}1,600 \\
b\end{array}$ & $\begin{array}{c}1,475 \\
\mathrm{Bc}\end{array}$ & $\begin{array}{c}2,800 \\
\mathrm{~A}\end{array}$ & $\begin{array}{c}3,015 \\
a\end{array}$ & $\begin{array}{c}3,075 \\
a \\
\end{array}$ & $\begin{array}{c}3,435 \\
\mathrm{~A}\end{array}$ \\
\hline Light-heavy & $\begin{array}{c}6,375 \\
a \\
\end{array}$ & $\begin{array}{c}5,725 \\
b \\
\end{array}$ & $\begin{array}{c}5,880 \\
a b\end{array}$ & $\begin{array}{c}5,525 \\
\text { B } \\
\end{array}$ & $\begin{array}{c}3,975 \\
\mathrm{Cd}\end{array}$ & $\begin{array}{c}3,690 \\
d\end{array}$ & $\begin{array}{c}4,400 \\
C \\
\end{array}$ & $\begin{array}{c}3,990 \\
\mathrm{Cd}\end{array}$ \\
\hline Sleek & $\begin{array}{c}2,970 \\
\mathrm{~d}\end{array}$ & $\begin{array}{c}3,175 \\
d\end{array}$ & $\begin{array}{c}3,300 \\
\mathrm{~cd}\end{array}$ & $\begin{array}{c}3,460 \\
\mathrm{Cd}\end{array}$ & $\begin{array}{c}4,200 \\
\mathrm{Ab}\end{array}$ & $\begin{array}{c}3,950 \\
\text { bc }\end{array}$ & $\begin{array}{c}3,990 \\
\text { bc }\end{array}$ & $\begin{array}{c}4,625 \\
\mathrm{~A}\end{array}$ \\
\hline Slippery & $\begin{array}{c}3,900 \\
d\end{array}$ & $\begin{array}{c}4,200 \\
\mathrm{~cd}\end{array}$ & $\begin{array}{c}4,700 \\
\text { bc }\end{array}$ & $\begin{array}{c}4,600 \\
\mathrm{Cd}\end{array}$ & $\begin{array}{c}5,700 \\
\mathrm{~A}\end{array}$ & $\begin{array}{c}5,400 \\
a b\end{array}$ & $\begin{array}{c}5,525 \\
a \\
\end{array}$ & $\begin{array}{c}5,950 \\
\mathrm{~A}\end{array}$ \\
\hline Compact & $\begin{array}{c}7,925 \\
a \\
\end{array}$ & $\begin{array}{c}7,725 \\
\mathrm{a} \\
\end{array}$ & $\begin{array}{c}7,625 \\
a \\
\end{array}$ & $\begin{array}{c}7,685 \\
\mathrm{~A}\end{array}$ & $\begin{array}{c}6,225 \\
\mathrm{~B}\end{array}$ & $\begin{array}{c}6,375 \\
\text { b }\end{array}$ & $\begin{array}{c}6,600 \\
b\end{array}$ & $\begin{array}{c}6,415 \\
B \\
\end{array}$ \\
\hline Flexible & $\begin{array}{c}2,675 \\
\text { bc }\end{array}$ & $\begin{array}{c}2,400 \\
C \\
\end{array}$ & $\begin{array}{c}2,895 \\
\text { bc }\end{array}$ & $\begin{array}{c}2,835 \\
\mathrm{Bc}\end{array}$ & $\begin{array}{c}4,600 \\
\mathrm{Ab}\end{array}$ & $\begin{array}{c}4,355 \\
a b\end{array}$ & $\begin{array}{c}4,370 \\
a b\end{array}$ & $\begin{array}{c}4,950 \\
\mathrm{~A}\end{array}$ \\
\hline Supple-stiff & $\begin{array}{c}7,840 \\
a \\
\end{array}$ & $\begin{array}{c}7,340 \\
a b\end{array}$ & $\begin{array}{c}7,125 \\
\mathrm{~b}\end{array}$ & $\begin{array}{l}7,350 \\
\mathrm{Ab}\end{array}$ & $\begin{array}{c}5,350 \\
C \\
\end{array}$ & $\begin{array}{c}5,410 \\
\mathrm{C} \\
\end{array}$ & $\begin{array}{c}5,275 \\
\mathrm{~cd}\end{array}$ & $\begin{array}{c}5,200 \\
\text { D } \\
\end{array}$ \\
\hline Wrinkly & $\begin{array}{c}7,815 \\
a\end{array}$ & $\begin{array}{c}6,825 \\
b\end{array}$ & $\begin{array}{c}6,475 \\
b\end{array}$ & $\begin{array}{c}6,625 \\
\text { B }\end{array}$ & $\begin{array}{c}5,275 \\
\mathrm{C}\end{array}$ & $\begin{array}{c}5,050 \\
\text { cd }\end{array}$ & $\begin{array}{l}4,525 \\
\text { cd }\end{array}$ & $\begin{array}{c}4,300 \\
\text { D }\end{array}$ \\
\hline
\end{tabular}




\section{REFERENCES}

1. Pierce, F. T. (1930), "Handle of cloth as a measurable quantity", Journal of Textile Institute, Vol. 21, pp. T377-T416.

2. Colina, M., Subhashm C.A. and David, P.B. (1999), "Effects of laundering on the sensory and mechanical properties of $1 * 1$ rib knitwear fabrics. Part II: changes in sensory and mechanical properties", Textile Research Journal, Vol. 69, No. 4, pp. 252-260.

3. Bueno, A. M. (1997), "L'évaluation de la main d'une étoffe“, Industrie Textile, Vol.1291, pp. 65-67.

4. Kawabata, S. (1980), "The standardisation and analysis of hand evaluation", Textile Mach. Soc. Japan, edition 2.

5. Bueno, A. M., Bernard, L., Vallier, P., Renner, M. (1997), "Instrumental measurement and macroscopic study of sanding and raising", Textile Research Journal, Vol. 67, No. 4, pp. 252-260.

6. Jevsnik, S., Stjepanovic, Z., H eikinheimo, L., and Gothih, K. (2011), "Effect of enzyme treatments on interlock knitted fabric", International Journal of Clothing Science and Technology, Vol. 23, No. 1, pp. 61-73.

7. Agarwal, G., Koehl, L. And Perwuelz, A. (2011), "Simultaneous influence of ageing and softener on mechanical properties of knitted textiles during life cycle of garment", International Journal of Clothing Science and Technology, Vol. 23, No. 2/3, pp. 152-169.

8. Philippe, F., Schacher, L. And Adolphe, D. (2003), "Characterisation of different finishing treatments using tactile sensory analysis", The fiber society spring 2003symposium-Loughborough University, UK, 30juin-2juillet. Actesctes, pp. 11-12.

9. Strazdiene, E., Ben Said, S., Gutauskas, M., Schacher, L. and Adolphe, D. C. (2006), "The evaluation of fabric treatment by Griff tester and sensory analysis", International Journal of Clothing Science and Technology, Vol. 18, No. 5, pp. 326-334.

10. Pietro, B., Ferrucio, B., Ester, F., Rosace, G. and Sergio, V. (2001), "Reference book of textile finishing", 1 edition.

11. Tarhan M and Sariisik M. A comparison among performance characteristics of various denim fading processes. Textile Research Journal 2009 ; 79 (4): 301.

12. Özgüney, A, Taşkin, C, Özçelik, G, Gürkan Ünal, P, Özerdem, A . (2009). "Handle properties of the woven fabrics made of compact yarns". Tekstil Ve Konfeksiyon, 19(2), 108-113.

13. Utlu Ala, D , İkiz, Y. (2017). "Subjective and objective evaluations of terry fabrics: effects of structural parameters and repeated laundering. Tekstil Ve Konfeksiyon, 27 (4), 361-365.

14. Sular V. and Kaplan S. (2011) Effects of different finishing processes on some performance characteristics of denim fabrics. Industria Textila; 62(6): 281288

15. Halleb, A. N., Sahnoun, M. And Cheikhrouhou, M. (2013), "Training and control of performance of tactile sensory panel", Journal of Applied Sciences, Vol.13, No. 3, pp. 366-376.

16. Halleb, A. N., Sahnoun, M. And Cheikhrouhou, M. (2015). The effect of washing treatments on the sensory properties of denim fabric. Textile Research Journal,85(2), 150-159. DOI: https://doi.org/10.1177/0040517514542971 